\title{
Visualization of the modelled degradation of building flooring systems in Building Maintenance
}

\author{
Farzad Khosrowshahi* \\ School of the Built Environment \& Engineering, Leeds Metropolitan University, UK \\ Parisa Ghodous \\ University Claude Bernard Lyon 1, Computer Science Department, France \\ $\&$ \\ Marjan Sarshar \\ College of Art Design and the Built Environment, Nottingham Trent University, UK
}

\begin{abstract}
The development of a maintenance programme for construction projects is a highly complex and data intensive undertaking. This exercise is characterised by the lack of relevant data on the one hand and the overwhelming amount of extraneous data on the other. The uncertainties and complexities have resulted in increased conservatism in the development of lifecycle evaluation of building maintenance programing, subsequently, these programmes tend to display the symptoms of either the maintenance actions being uneconomical or fall short of providing the appropriate service to the users of the building. The current research project is based on the premise that the visual approach will facilitate a just-in-time solution to maintenance scheduling, hence, the use of virtual simulation of the building is proposed. The broader aim of this research is to develop a complete building maintenance programme through visualisation of buildings as they degrade over time. Here, the focus is on the flooring system and the manner they degrade over time. This requires a better understanding of their pattern and rate of usage. To this end, Anthroposophy and Anthropocentric descriptions of human movement pattern have been used to describe the behaviour of 'subjects' and subsequently represent the pattern and density of the degradation of flooring systems. The mathematics representing this behaviour has been developed which enables it to be embedded into the proposed overall visual building maintenance model.
\end{abstract}

\section{INTRODUCTION}

The strife for maximisation of lifecycle value through sustainability by addressing social, technological, economic, and regulatory requirements, has been recognised more than ever before (Pitts 2008). Some of the challenges associated with collaborative working, applicable to lifecycle evaluation of a building, are examined by Shen, W. et al (2010). Reflecting the outcome of a Canadian industry survey by Froese, T. et al (2007), they have highlighted the perceived importance of webbased collaboration and project management systems. Inherently, sustainability needs to reflect the current needs without undermining the needs of future users in relation to health and safety, energy efficiency and thermal comfort (WCED 1987). To this end, it has been long realised that the design should be able to respond to changing circumstances (Russell and Moffatt, 2001). It is common knowledge that in comparison with building design, construction and demolition, the maintenance phase of building project is critical and assumes by far the greatest proportion of the overall time and cost (Chinyio and Gameson 2009). Similarly, by far, the greatest proportion of energy consumption and emissions come from the usephase (Keoleian et al, 2001) and in the case of commercial buildings it can be as high as 95\% (Scheuer \& Keoleian, 2001). Undue lack of attention to building maintenance will inevitably result in building component decay leading to excessive maintenance costs (Spedding, 1994). The growth of PFI (private finance initiative) and PPP (private public partnerships) has hinted a fundamental change of the nature of the construction industry from a product and to servicebase (Akintoye et el 2003). This involves moving the balance from capital investment to revenue generation. As a consequence, the interest in lifecycle performance of buildings and the provision of service over the life of a building has been on the increase. Subsequently, the development of an appropriate and accurate long-term maintenance schedule is of paramount importance. Life Cycle Assessment (LCA), as defined by BS EN 14040:2006 (BSi 2006), is an iterative process of assessing the environmental impact of a product, process or service 
(Baumann and Tillman, 2010). It is a methodology covering all processes from the extraction of raw materials through to disposal (Shah et al., 2010). LCA is an effective way for the analysis of performance-based sustainability design, by quantifying environmental, social and economic indicators (Finnveden et al., 2009). Over the years, there have been a number of lifecycle costing methods for use (Stone 1980; Flanagan and Norman 1983; Robinson 1984). General Life Cycle Analysis methodologies such as that by the International Standard Organisation (ISO) series 1404014043 (ISO 2006) are applicable to a range of products, processes or services. Those specific to construction tend to focus on individual materials and components and not the totality of the building system (Zabalza, B. I., Aranda, U. A. and Scarpellini S, 2009). The same is true about general lifecycle evaluation of building performance (Rapp and George, 1998 and Wordsworth, 2001). However, current methods tend to lack the efficiency that is characteristic of the Just-in-time method. As an example, Ng, S. T., et al., (2009) address the wastes associated buffer stock to to minimise labour and plant resources staying idle.

This paper proposes a model that provides an alternative approach to decision making concerning the maintenance of buildings and structures. The overall project consists of a study into the time-related behaviour of building components in response to their environment and the events acting upon them. The project will ultimately develop a complete 4D visual model of building life through representation of the degradation of each individual building component. This requires definition of mathematical behaviour and representation of all building components in response to events acting on them. It is argued that the visual method enables effective decision making for the provision of just-in-time maintenance scheduling for most building components. The paper describes the overall visual building degradation model before providing details of the case for flooring systems, for which the determination of people pattern of movement is formulated and represented mathematically. The paper also facilitates a methodology for visual representation of the decay of flooring system.

\section{BUILDING MAINTENANCE}

Construction maintenance has undergone three generations of development ranging from the combination of 'maintenance on failure' to 'preventative planned maintenance' and 'time-based maintenance'. A systematic approach to maintenance management, supported by computer systems, commenced during early 1970s. However, it was by early 1980s before the use of improved computer technology enabled more sophisticated and complex calculations as well as better use of databases (Pettit 1983). These enhancements continued with the introduction of desktop computing which was instrumental in popularising the building maintenance management process. The qualitative improvement in the power of computers in conjunction with the increased participation of wider range of users resulted in software vendors and inhouse developers to engage in new enhanced approaches to the problem. With the establishment of the Building Cost Information System (BCIS) by the RICS in the early 1970s and the establishment of Building Maintenance Cost Information System (BMCIS) providing further focus on the maintenance cost information, the path was paved for a more orchestrated analysis and modeling the building maintenance cost. The provision of data together with the increasing awareness and concern for the post-construction costs resulted in the 1980s to become the era of experimentation and examination of lifecycle costing from several angles. These include Flanagan and Norman (1983), Bromilow et. al. (1984) and Spedding (1994) (incorporating several articles on the subject). The developments in the early periods resulted in a revised and improved systems including the use of centralised databases, incorporation of conditional assessments, repair scheduling and budget development (Jones and Collis, 1996). Since the latter part of 1990s the efforts to improve the acquisition, refinement and management of data have been on the increase. An example is the project OSCON (Aouad et. al. 1997) where a centralised database facilitates full integration of several construction activities. This project was later extended to include maintenance activities providing and using data from the centralised database. The above is also included enhancements in the representation of data with the aid of visualisation tools.

Despite the progress, a widespread discontent has existed within the industry, as all current systems tend to simply automate the process and the level of accuracy has been less than satisfactory. Building maintenance and facilities management have often been viewed as a supportive rather than core activity (Waheed and Fernie2009). Having identified 9 activities associated with maintenance, Jones and Collis (1996) undertook a survey of companies involved in maintenance and identified that the computer system of over $60 \%$ of their respondents used only 3 or less than 3 activities. In a later attempt Jones et al. (1999) conducted a more comprehensive survey targeting various organisations associated with construction industry and with further association with building maintenance. These consisted of district councils, housing associations, private practice, universities, retail outlets, health authorities \& government associations and light industries. With the total sample size of 678 , they concluded that the computerised maintenance systems tend to operate well only in limited areas of application. However, there are several other areas where advancements are essential. As expected an area 
which is particularly underdeveloped is the maintenance planning. The shortcoming in building maintenance improvement remains to-date and the lack of "free thinking" in the delivery of building maintenance services has been recognised (RICS 2009). Indeed, the current systems are little more than a sophisticated calculation machines. Due to the scale of the problem, uncertainties of the future events and the inherent complexities associated with holistic maintenance programming, it is impractical to develop a model that encompasses all elements and aspects of building maintenance. Subsequently, researchers have searched for more practical solutions. For example, Al-Hajj and Horner (1998) apply the cost-significance method in order to identify those elements which account for the majority of the costs, thus eliminating a large proportion of elements the contribution of which is justifiably insignificant.

Furthermore, the current best practices are somewhat simplistic. Each component is considered individually and in isolation from other components. The interaction of events, on the one hand, and components on the other, make it very difficult to apply a holistic approach to maintenance programming (Khosrowshahi and Alani, 2003). Also, the current approaches are based on data relating to components from past projects. This implies that the data is also reflective of the total environment surrounding the component, whereas, in reality, circumstances are highly diversified. The changing of even one variable could have a significant impact on the behaviour of the component. Therefore, the examination of scenarios is possible only when historical data are available for all variety of diverse situations.

\section{VISUAL BUILDING MAINTENANCE MODEL}

Human vision and domain expertise are powerful tools and together with computational tools make it possible to turn large heterogeneous data volumes into information (interpreted data) and, subsequently, into knowledge (understanding derived from integrating information). Visualisation can encompass a variety of topics ranging from information visualisation to scientific visualisation, virtual reality, multi-media, etc. While in construction fields virtual reality, multi-media and immersive visualisation are more familiar terms, the benefits of Information Visualisation concepts are yet to be realised (Rangaraju and Terk, 2001). This has been the case in the UK as it is in the US (Rhodes, 2012). Some isolated cases include Kuhner, et al., (2004): They adopt spacetrees approach to the complex data structuring for visualisation of indoor air flow geometries. Also, Jha (2006) explores the potential use of visualisation to achieve highway improvements and offers a fuzzy logic-based model to measure the benefits.

According to Card,et at.(1999) Information Visualization is "The use of computer-supported, interactive, visual representations of abstract data to amplify cognition". Elsewhere in the text they describe abstract data as that which does not have any 'obvious spatial mapping...nonphysically based'. Spence (2001) does not define the term explicitly, but says "the need to display the physical 'thing' is not important... and is often entirely irrelevant... in information visualization". Chen (1999) adds the qualifier 'abstract' using 'abstract information visualization' for clarity and also does not define the term.

The visualisation techniques can aid lifecycle decision making in various ways. Enabling informed design choices that underpins sustainability remains as an on-going challenge within the industry (BSi, 2012). With advances in visualisation technology and the paradigm shift in the manner stakeholders collaborate and interact (Rosenman, et al. 2007), the ability to simulate the time-based behaviour of building elements can assist decisions relating to both design and scheduling. Some of the challenges associated with collaborative working, applicable to lifecycle evaluation of a building, are examined by Shen, W. et al (2010). Reflecting the outcome of a Canadian industry survey by Froese, T. et al (2007), they have highlighted the perceived importance of web-based collaboration and project management systems. While the visualisation of building operation has long been addressed by researchers and practitioners (Kamat and Martinez, 2001, and Dawood and Mallasi, 2006), the same has not been the case for building operation phase. The current research is concerned with the concept of $4 \mathrm{D}$ visualisation which reflects the state of building 'through time'. The proposed visual approach will facilitate the implementation of the proposed just-intime method for maintenance programming. Such tools have already been exploited by researchers for various purposes such as building design and analysis of construction equipment (Lipman and Reed, 2000), as decision tools (Flanagan, 2002) and for planning and scheduling (Haymaker and Fischer 2001). The proposed visual approach will provide an integrated approach to the evaluation of the status of building elements. This approach has the potential to facilitate development of an optimum maintenance programme.

\subsection{Generalised Building Visual Simulation Model}

The overall generalised model is given in Figure 1. There are three parts to the visualisation model, namely, data management, simulation and presentation. The knowledge associated with the building components is encapsulated 
into data-objects that will be incorporated into a heterogeneous database containing component details, timerelated behaviour and their visual attributes. The proposed model is data-centric and its multi-directional (as opposed to uni-directional down-stream data transfer) approach is an imperative part of the flexibility that is required for such a complex and large-scale project. The process commences with the CAD drawing that represents the initial state of the building. It contains the usual CAD data as well as extended attributes such as parameters, element specifications and project environmental definition. The 3D information model can be driven directly or from the CAD data. All data flow through the system are in XML (the industry defacto, XML format has been selected as the transportation file format and to manage the information in a hierarchical form). For a given project situation (simulated by Event Simulation System), the lifecycle simulator transforms the Object-based Building from state $t_{i}$ to state $t_{j}$. This XML-based data at state $t_{j}$ is then submitted to the Visual User Interface for visuals representation of the building at state $t_{j}$. The model is a generic outlay that eparates data from processing and visualisation systems. The alternative to CAD is to have direct access to IFCenabled objects within a BIM solution. Additional visual attributes will include time-related behaviour which defines the visual status of building objects at different points in time.

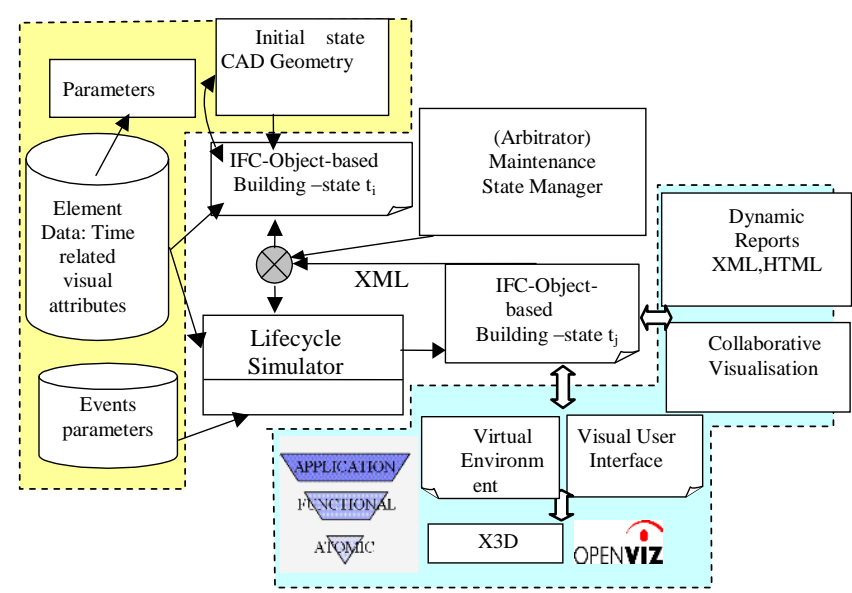

Figure 1 Generalised Simulation Model

\subsection{Visual User Interface}

Integrated building lifecycle evaluation systems are now available with the aid of BIM solution systems (Holness G., 2008). The dynamic real-time integrated modelling extends the previous $2 \mathrm{D}$ graphical capabilities to include intelligent objects containing information about material properties, spatial relationships, geometry and several other attributes (Holness G, 2008 and Krygiel, and Nies, 2008). Alda et al
(2006) extend the concept to include an integrated multiagent system that combines the capabilities of human experts and software agents. The object nature of the model allows us to define additional attributes, such as enhanced visual attributes representative of the visual status of building components throughout their entire life. It is envisaged that in time BIM has the potential to provide a viable platform for both analysis and visual representation. However, for now, because of extensive analytical processes, interaction with current BIM software is impractical. At best, BIM systems can offer a complicated way of visual representation. As noted earlier, here, the overall simulation model is based on a generic approach to the lifecycle visualisation rather than relying on a BIM platform. Indeed, the visual component (Visual User Interface) is a key element of the overall model. The concept is sporadic but not new to construction. Among rare attempts to exploit scene graph to visualisation within Construction fields is by Kamat \& Martinez (2002). They apply the scene graph concept to develop a CADindependent generic 3D realistic visualisation for construction operations. They take the notion further by developing an algorithm to facilitate high speed and concurrent simulation (Rekapalli, Martınez and Kamat, 2009).

A keystone in the model is the component way of thinking within the context of object-oriented modelling. This enables short development time, scalability, extensibility and reusability. The applications will be based on a layered component framework. In the visual stage, there are three levels of component: At the 'Atomic' level, components are very low-level, high-performance and typically underlying data structure. Here, they are linked with X3D and OpenViz graphics platforms. 'Functional' levels are the middle-tier components that are constituted by one or more atomic components. These typically implement the general functionality, for example, for a Maintenance viewer. Application, level components are constituted by the combination of one or more functional components. These are actually customer ready applications such as Decision Support Systems. All visualisation components are lightweight and involve minimum number of interfaces. The purpose of this task is to develop a virtual reality-based component that will link the CAD geometry model to the maintenance model of the building and provide a 3D virtual environment to allow for visual examination of building degradation. This component supports a sophisticated navigation model that includes object examination, scene fly-through and walkthrough modes. The VUI controls the entire process from data to $3 \mathrm{D}$ views. X3D provides the core graphics technology to support a broad range of 3D applications and complies with VE requirements. X3D has proven itself by evolving the widely supported 3D functionality of VRML. The choice of X3D provides access to more tools, content 
and compatibility with other applications. The model will provide Web-enabled, interactive 2D and 3D visualisation and analysis into maintenance portfolio in standard document formats, such as XML, HTML and MSWord. It also facilitates flexibility, compatibility and a path for MPEG-4 support. The model is extended to 4D (trough time) by the introduction of a time-related network analysis of the project. The project schedule database will contain attributes of building components that will enable visual simulation at any point in time.

\subsection{Degradation of Flooring System}

The focus of this paper is on the building flooring system. The cases where informed LCA is applied to the choice of the flooring system are few and far in between. These studies tend to focus on case studies of particular scenarios. One example is a new school project where a comparison is made between the choice of carpet and linoleum: A lifespan of 15 years was estimated which suggests the possibility of the need to change the flooring system three times over the whole life of the school. This examination also included the impact of the choice on the energy performance of the building, which also included the recycling prospects (Capperm et al., 2012). Similar to other components, the decay of a flooring system is influenced by several factors including the fabric of the carpet, the environment and the period of usage. The impact of each variable on the state of the carpet is implemented through the application of coefficient which is applied to the density pattern of movement. This data can be partly obtained from the manufacturers and some are derived through statistical analysis of data.

The visual representation of the decay process of any building component offers a number of challenges associated with the simulation of time-based behaviour of the component. The combination of the simulation of component behaviour and its visual representation is a wellknown phenomenon in the constriction domain. Most notably, the simulation and visualisation of crane movement has had a long evolutionary path (Kang, and Miranda, 2009). However, the simulation of the time-based degradation is somewhat unknown. Moreover, the examination of the flooring systems offers additional challenges, particularly those related to the pattern of usage of flooring systems as well as their visual representation. Therefore, the process requires addressing the following challenges.

1. Pattern of usage: flooring systems are utilised in a non-uniform fashion. There are parts that remain almost unaffected over time and there are parts that are subjected to excessive degradation. The evaluation of each individual scenario is impractical, thus a consistent method should be used to represent the pattern of usage for a given situation. Further, the method should be represented mathematically so it could be embedded into the overall model.

2. Mapping: the realistic visual representation of the usage should be based on both the level of degradation and the pattern of usage: The level of usage is then mapped on the pattern of usage.

3. Visual representation of the usage: a method is required to reflect the level of the degradation and represent it in a visual form. Here, for practical reasons, the representation is undertaken through the use of VRML.

\section{THE PATTERN OF USAGE}

The observation of any used flooring system reveals that it does not degrade uniformly: certain parts attract more traffic and others like the edges or those covered by objects such as a table are hardly affected through time. This nonuniformity of the usage has a direct impact on the degradation of the flooring system. Therefore, the true visualisation of the degradation of the flooring system should initially identify the pattern of usage for each flooring situation and reflect the impact of time accordingly. However, there are many building components each with vast variety of choices and features. Also there are many varieties of routes such as corridors and rooms and there are several types of usage. To cater for all these possibilities, on a case-to-case basis, it is necessary to identify and classify a large number of scenarios. But, a scenario-based approach is laborious and requires continuous updating to cater for new situations. These complexities render the scenario-based approach impractical. It is imperative that visualisation is based on generic algorithm whereby, the impact of events and time is defined mathematically and visualised accordingly. Further, the incorporation of the flooring system into the overall time-based visualisation model requires an automated mechanism, underpinned by mathematical representation.

\subsection{Human Movement Pattern - Anthropology}

There have been a number of 'wayfinding' and 'path-oftravel' studies such as Apelt, et al, (2007). These works tend to address peoples' movement behaviour in adverse situations such as fire escape. Therefore, the primary focus of these works is on the examination of the route that occupiers take in emergency situations. However, no previous study has been identified which examines people's general movement behaviour. Here, the subject-matter is examined from anthropological perspective. Traditionally, anthropology has been concerned with the four fields of linguistic, biological/physical, cultural and archaeology, but, there has been a considerable realization of practical 
implications of anthropology and its relevance to other disciplines and professions (Puntenney, 1995). Further, this branch of science and those peripheral to it have developed insight into behavioural as well as biological facets of humans as individuals and as a member of groups of individuals. Robinson and Nims (1996) integrate anthropology with sociology, cognitive science, ergonomics and business to develop a better understanding of how people interact with objects. Jordan (1995) extends the applicability of anthropology from individuals to organizational level. Also, anthropological view-point has been used in a variety of research into users' needs. Wilcox (1996), for instance, explores anthropology for product design. While distinguishing between design and art, for instance, Barley (1992) argues that for the examination of products of other people, 'design' tends to be a better term than 'art'. Schensul(1996) applies anthropology to design concepts in order to ensure that, in an attempt to solve one problem, new products do not give rise to new problems. Nardi and Reilly (1996) explore 'interactive ethnography' to extend the application of anthropology beyond design process to marketing and management.

The examination of people's behaviour within their spatial layout can be based on 'activity' or 'behavioural' settings. While the activity setting is concerned with the organisation of the sequence of activities (Chapin 1968), the behavioural setting looks at the relationship between the settings and the recurring pattern of behaviour (Barker 1968). Traditionally, architectural designers tend to be concerned with spatial layouts that cater for the activity patterns of the building users (Lang, 1974). But there have been equal attention to the need to understand the behavioural constituents that underpin the activities (Hall, 1962; Hall 1966; Sommer 1969). Subsequently, this research will examine the human special behaviour through behavioural setting.

Human behaviour is influence by several factors such as their physiology, culture and social group membership. One set of behaviour that concerns this project is the human movement pattern as discussed by Dreyfuss (1967). In search for a better understanding of human movement pattern through their behavioural setting, this research lends itself on the anthropological science of human kind and behaviour. Two basic behaviours of humans relate to their desire to acquire wisdom (Anthroposophy) and their centric tendencies (Anthropocentric). Therefore, on the one hand, humans tend to place themselves in the centre of spaces and on the other hand, they distance themselves in order to acquire more wisdom. This would be the behaviour of an individual (subject). Once the second subject is added then the resulting behaviour is the combined effect of the two subjects. Equally, the introduction of the third, fourth and $\mathrm{n}^{\text {th }}$ subjects will demonstrate a pattern and lead to generalised combined behaviour.

\subsection{Anthropy}

In this paper, the term Anthropy is introduced to provide the mathematical representation of people's generalised movement pattern. An anthropy is therefore, defined in terms of the pattern of usage of a flooring systems by a colony of users consisting of one or more individuals or objects affecting the life status of the flooring system. Therefore, anthropy is independent of the nature of the flooring system. The time-related nature of anthropy suggests that an anthropy is also a reflection of the intensity of usage referred to as the Anthro-intensity. This variable specifies the amount of time the route is subjected to the given movement pattern.

Mathematical representation of anthropy will enable its universal application and embedment into the overall visual building degradation model. It stands to reason and is evident from the review of data published by many manufacturers, that the relationship between anthrointensity and time is linear. In other words, the longer the flooring system is used, the higher the value of its anthrointensity will be, and the increase is directly proportional to time. On the other hand, the mathematics of the movement pattern is less deterministic and relies on the use of probability functions, in conjunction with manufacturers' specification data.

In order to develop a mathematical representation of this combined behaviour, we initially look at the work by Tregenza (1976) which suggests that in a given corridor, the flow rate is $\mathrm{f}$ (speed, density, width) given by, Flow rate = mean speed $x$ mean density $x$ width.

Equally, the Density is $\mathrm{f}$ (Speed, Width). Therefore, for a given flow rate (people per second), the number of people who can be accommodated in a corridor is determined by their walking speed and the width of the corridor. Here, since the walking Speed is already expressed by a normal distribution (Tregenza 1976), and the width being a constant, therefore, the distribution of the movement density follows the standard normal distribution, which assumes the following expression.

$$
f(x)=\frac{1}{\sqrt{2 \pi}} e^{-\frac{x^{2}}{2}}
$$

In order to apply control over the positioning of the distribution, an additional parameter $y$ is introduced to equation (1). Therefore, in the absence of external biases the expression is a one dimensional (line) representation of the behavioural pattern of an individual (subject). This representation is referred to as anthropy and is given by; 


$$
f(x, y)=\frac{1}{\sqrt{2 \pi}} e^{-\frac{(y-x)^{2}}{2}}
$$

where,

$x$ is the random variable and $y$ determines the degree of centrality

The value of $y$ is determined by anthropologic exponentially-based expression. Here, tangible examples are used for demonstration purposes. Graph $a$, in Figure 2, shows the centrality selected at 2 which is almost in the middle of the arbitrary scale from 0 to $5 \mathrm{~m}$. This is an arbitrary value used to represent the overall width and $y$ is selected as 2 to suggest near-centrality. The function is given by;

$$
a(x)=f(x, 2)
$$

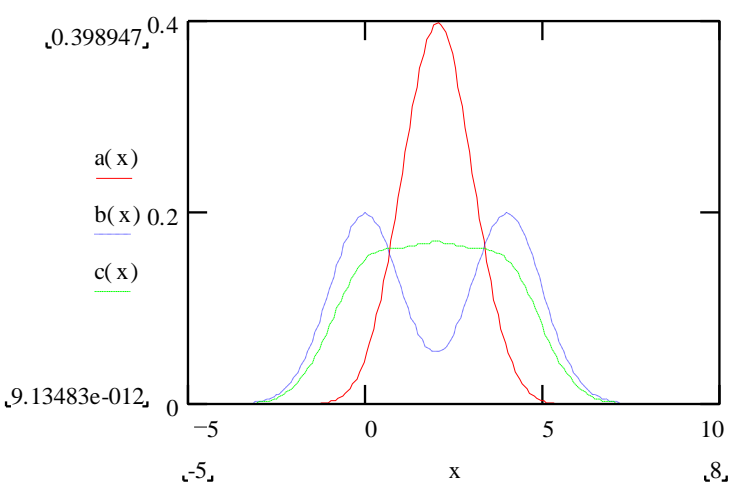

Figure 2 The probability of presentation of one, two and three subjects based on Anthropy

As the number of subjects increases, the centrality of the combined curves is altered. This is shown in Figure 2 by the following expressions representing graphs $b$ and $c$ for two and three subjects respectively. These are given by;

$$
\begin{aligned}
& b(x):=\frac{f(x, 0)+f(x, 4)}{2} \\
& c(x):=\frac{f(x, 0)+f(x, 2)+f(x, 4)}{3}
\end{aligned}
$$

For the model to represent the population of a colony of subjects, it should be expanded to represent $n$ number of subjects, when $n$ approaches infinity. The expression representing the behaviour of a colony $g(x)$ is as follows;

$$
g(x)=\int_{y=i}^{j} \frac{f(x, y)}{y} d y
$$

The resulting graph in Figure 3 shows the behaviour of $n$ number of subjects as approaches infinity between $\mathrm{i}=1$ and $\mathrm{j}=5$. Evidently, this curve displays similar behaviour to normal distribution curves. Here the lateral displacement is represented by $i$ from 1 to 5 which is an arbitrary and relative value for demonstration purposes.

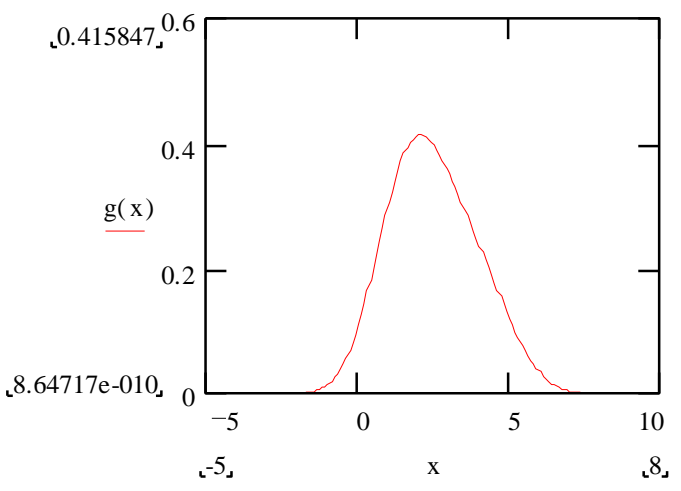

Figure 3 Shows $g(x)$ for $\mathrm{i}=1$ and $\mathrm{j}=5$

\subsection{Flat-Anthropy}

Figures 2 and 3, are the one dimensional (line) representation of the pattern of behaviour. However, the density or probability of appearance is better shown in Figure 4 which is the two dimensional (flat) representation.

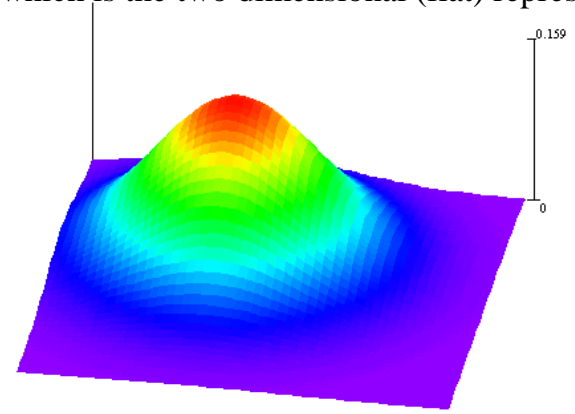

Figure 4 Shows the two dimensional representation of the pattern

The plan view of the Figure 4, given in Figure 5, shows the density of appearance where lighter colours represent the highest density (probability) and darker colours represent the lowest density (probability). This phenomenon is referred to as the flat-anthropy. 


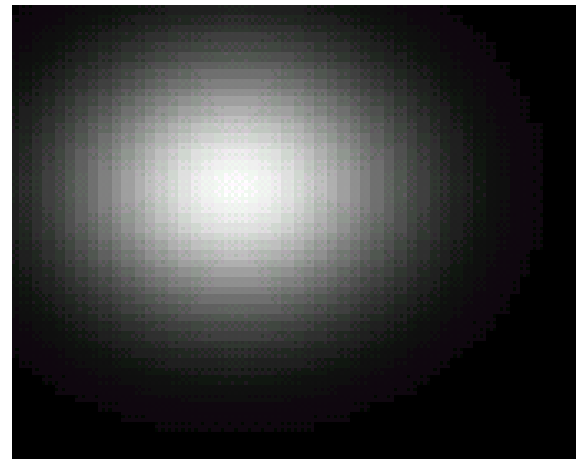

Figure 5 presentation of the probability of appearance of ' $n$ ' creature in 2-D

\subsection{Long-Anthropy}

The extrapolation of the same principal and its projection over a long two dimensional length (corridor) will produce a pattern of density (probability of appearance) along the corridor. Figure 6 , is the representation along a corridor with one entrance (on the right) and Figure 7, is the same for a corridor with a flow (two entrances at each end, both with similar properties).

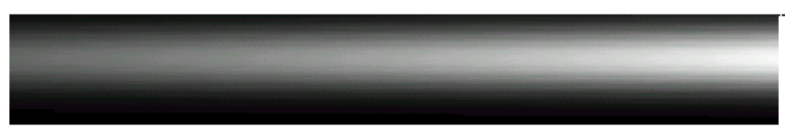

Figure 6 Presentation of probability of appearance of $n$ subjects in a Corridor with one entry

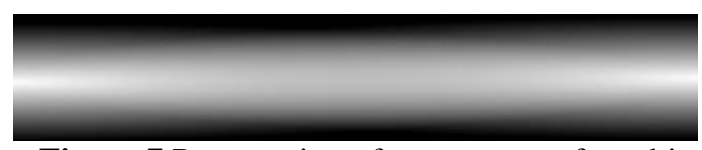

Figure 7 Presentation of appearance of $n$ subjects in a Corridor with two entries

Figures 6, and 7, represent straightforward corridors with predictable behaviours. However, in real life there are varieties of configurations and layouts that the environment can assume. For instance, the entrances may not be symmetrically placed. The methodology for the incorporation of all possible configurations and layouts is based on the superimposition of blocks of basic known flat and long anthropy models. Figure 8, is the two dimensional representation of the movement density pattern of an empty room with two communal entrances on two adjacent walls. This pattern is generated by positioning and combining three corridors together with a flat anthropy. The position of the corridors of movement is shown on the figure.

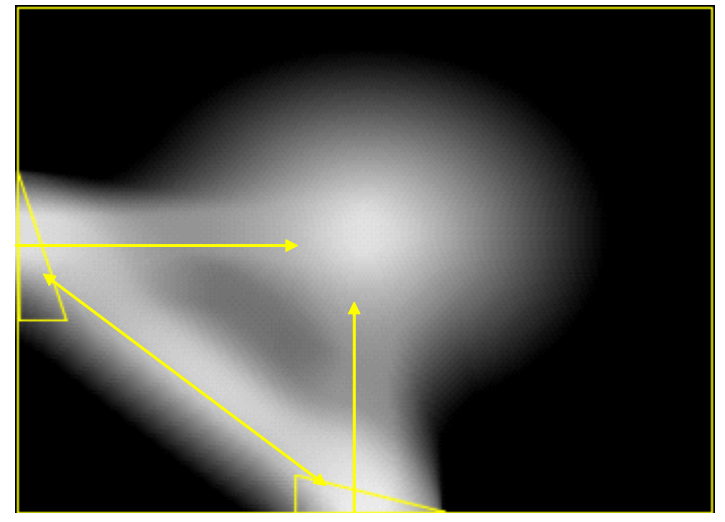

Figure 8 Movement density pattern for a room with two communal doors

\subsection{Anti-Anthropy}

The behaviours described so far apply to non-biased and un-intervened circumstances. However, almost always, spaces are intervened by external objects which tend to profoundly affect the movement behaviour. For instance, by placing an observatory telescope at the end of the corridor in Figure 6, the pattern of behaviour will change significantly. Also, by introducing an intervention such as placing a round table in the middle of the room, the pattern of movement on and around the obstacle (round table) will be affected. This will in turn increase the complexity of the movement pattern. As shown in Figure 9, by placing the round table in the middle of the room with one communal entrance the movement density will assume a different pattern to that of a room without a round table. For start, the space underneath the table is no longer accessible. This implies a zero density (zero probability of occurrence) for the occupied area. Further, the space in the vicinity of the table, immediately surrounding it, is also restricted. In effect, the round table has created an anti-antrophy, which behaves similar to antrophy (Figures 4 and 5), but in an inverse order. Therefore, the density pattern shown in Figure 9 is generated by superimposing an anti-anthropy on an anthropy.

\section{MAPPING THE PATTERN OF USAGE - WEIGHTED TEXTURE MAPPING}

As noted, the pattern of usage is non-uniform. It is determined by the spatial behaviour of users, which is constructed through the application of a series of anthropies and anti-anthropies. The method of simulation adopted in this research is based on overlapping the texture of the used floor (based on the density movement pattern) on the texture of an unused floor. This is carried out through 
weighted texture mapping, where the colour attributes of unused and used carpets are aggregated on the basis of weightings produced by the density pattern. This is facilitated by a Visual Basic programme which identifies the colour attributes of the used areas and map this pattern over the original (or previous state) area, altering the weightings of colour attributes. In Figure 10, an unused carpet is contrasted against a fully-used version of the same type of carpet. The Visual Basic programme is used to calculated and map the weighted textures of the unused carpet and movement density pattern of use in Figure 8. The result is shown in Figure 11, highlighting the affected area.

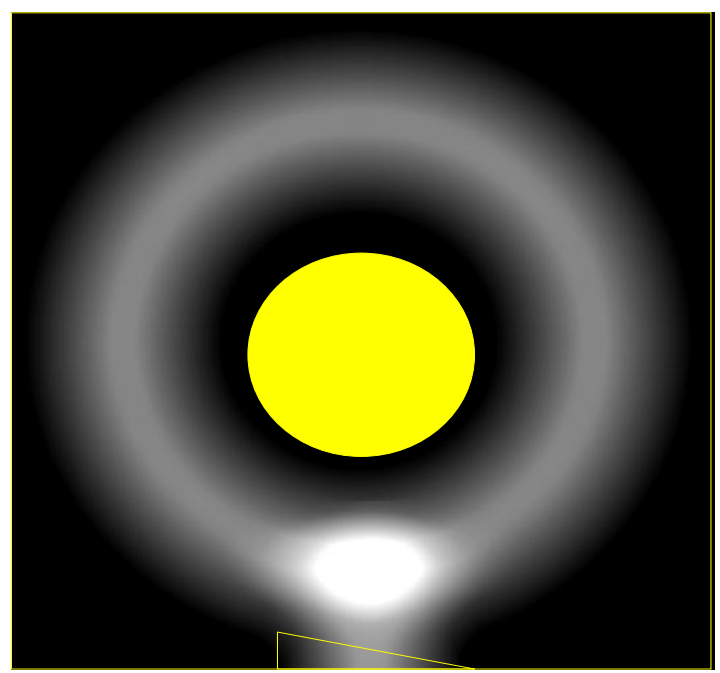

Figure 9 Movement density pattern for a room with one door and circular table on centre.

\section{VISUAL REPRESENTATION THROUGH VRML}

For demonstration purpose and proof of concept, VRML is used, as it provides a simple script-base interface. The use of textures and texture mappings is an straightforward task within VRML (ISO/IEC 14772-1: 1997 and VRML2.0 final Spec). Since the movement density is a localised phenomenon (only affecting certain areas), the simulation of localised degradation is not directly possible through VRML. Therefore, initially, the original texture is applied to the whole area then, the movement density pattern is superimposed. The use of VRML for simulation of flooring degradation is demonstrated in Figure 12: the carpet is degraded based on the intensity and pattern of usage shown previously. Figure 13, shows the same room with only one entrance. The Figure shows the impact of the introduction of a round table, which is implemented through the use of an anti-anthropy.

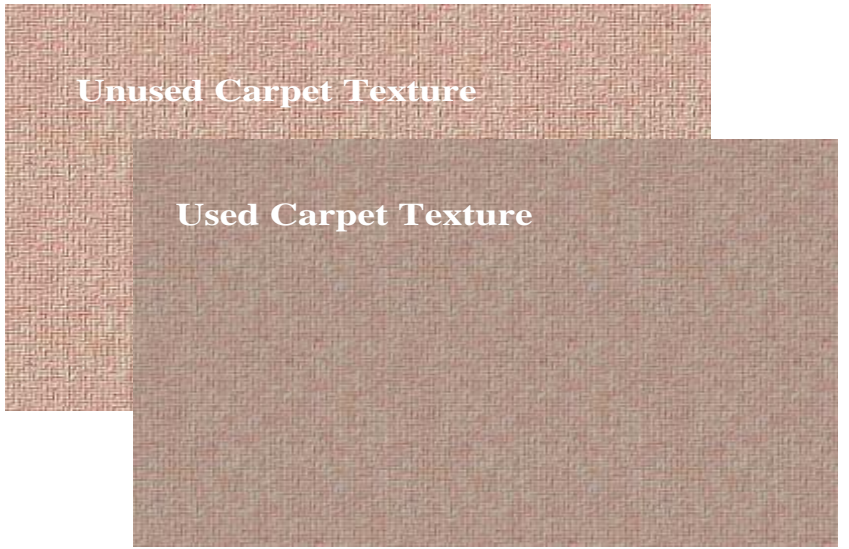

Figure 10 Used and unused carpet texture

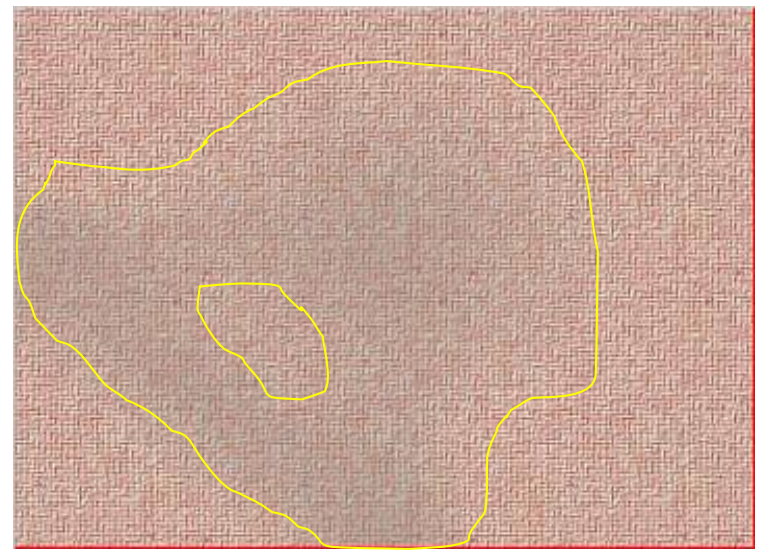

Figure 11 mapped used carpet texture

\section{FUTURE WORK}

The research will address the above issues. The significance of the work is that it will help to facilitate the implementation of just-in-time building maintenance scheduling based on visual perception of degradation of building components. The aim of the research is to develop a methodology for visual representation of the flooring systems and its embedment into the overall visual building degradation model. The achievement of this aim requires formulation of human movement pattern that affects flooring usage. In conjunction with authors' other publications such as Khosrowshahi and Alani (2011) and Khosrowshahi and Banissi (2001), never before, just-in-time maintenance decisions 
are made on the basis of visual inspection of time-based behaviour of a building components: or anthropological concepts used to define the pattern of usage of flooring systems, then expressed in such a way that it is simply applied. However, there are aspects of the work that require further justification.

Although, this work has deliberately moved away from scenario-based approach to simulation, further empirical tests will be carried out which will use scenarios to verify the findings of this work. Also, it is envisaged that scenario planning approach may be an appropriate methodology in practical areas such as the one for energy evaluation by the Sustainable Energy Management in the Built Environment (SEMBE, 2008).

While the aforementioned anthropological principles are well established and somewhat straight forward, it is likely that in practice there will be variations due to such issues as culture. There are many such variables and depending on the expected level of pragmatism these need to be researched independently. However, it is not the primary objective of this research to attempt to provide a precise prediction of the future, as this exercise might be somewhat futile, whereas, as argued by Gil and Beckman (2009), it is the approach that promotes 'serious thinking' and offer a more viable route to objective decision making.

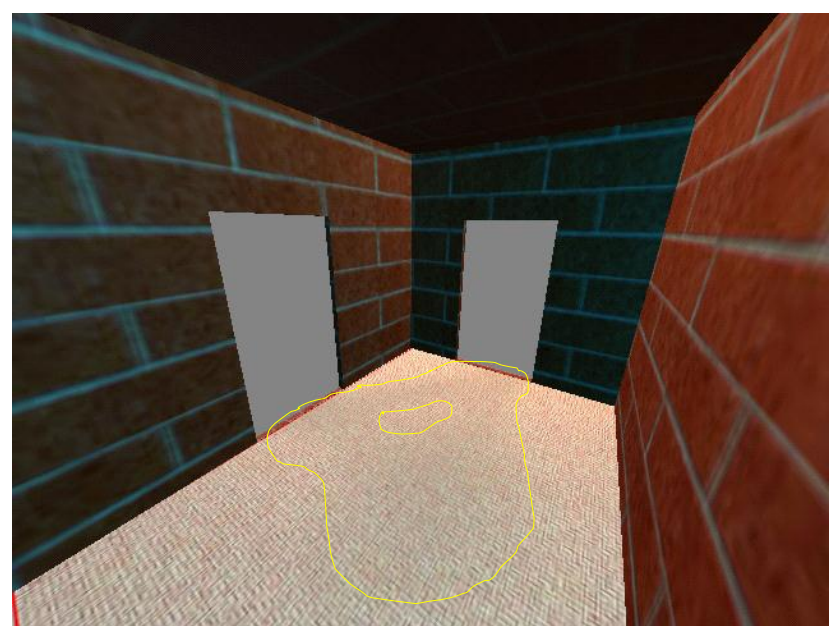

Figure 12 A room with two doors after two years

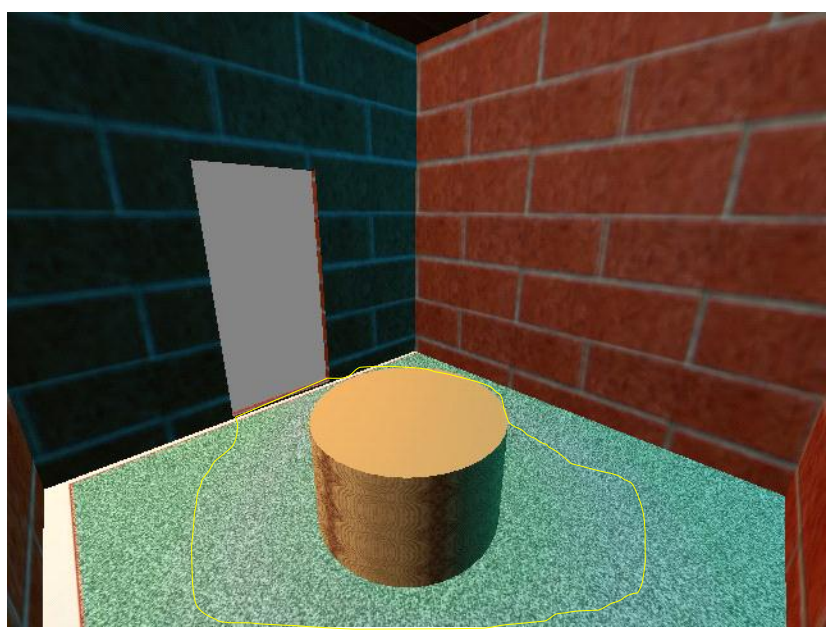

Figure 13, A room with circular table in centre after 18 months of use

\section{CONCLUSIONS}

The paper reiterates the pitfalls of the current building maintenance systems and highlights the advantages of the just-in-time approach. It is suggested that just-in-time maintenance can be achieved in a virtual environment by visualising the degradation of building components over time. An overview model of the proposed virtual environment is presented which consists of three sections: data management, simulation and presentation (Visual User Interface). The implementation of the model required formulation of the behaviour of all building components over time, and their visual representation. The focus of the paper was on the flooring system which offered additional challenges associated with the evaluation and formulation of their pattern of usage, as different parts of floors are degraded according to their respective type and level of usage. It was noted that a scenario-based approach is laborious and an algorithmic representation will offer a more practical alternative. To this end, the behavioural setting' view of anthropology was explored and exploited: Accordingly, conscious systems such as humans tend to engage in a conflicting exercise of tending to position themselves in the centre of their environment and yet maintaining distance from one another. This will allow them to exercise their centric tendencies (Anthropocentric) while acquiring wisdom (Anthroposophy). This resulted in the incremental development of the generalized mathematical representation of the density movement pattern of flooring systems. The visual representation was then implemented through weighted texture mapping of the movement density pattern on used and unused floor textures. The model provided the basic building blocks for 
extending the concept to more complex flooring configurations and layouts. The resulting concept was termed 'anthropy' which formed the basis for the simulation of both the pattern of usage as well as obstacles, such as a table, that inhibit movements, namely 'antianthropy'. The mathematical model also facilitates the simulation of other situations such as single-ended and double-ended corridors.

\section{REFERENCES}

Akintoye A., Beck M. \& Hardcastle C., (2003) Public private partnerships, Blackwell Publishing London 2003

Alda, S., Bilek, J., Cremers, A. B. and Hartmann, D. (2006) Awareness and workflow based coordination of networked co-operations in structural designs. ITcom, 11(2006), pp 489-507

Al-Hajj, A. and Horner, M. W. (1998) Modelling the running costs of buildings, Construction Management and Economics, 16, 459-470.

Aouad, G., Child, T., Marir, F., and Brandon, P. (1997) Developing a conceptual model for an integrated database, Proceedings of Intelligent Information Systems, Bahama, December, 316-320

Apelt, R. and Crawford, J. and Hogan, David J. (2007) Wayfinding Design Guidelines. Cooperative Research Centre (CRC) for Construction Innovation, (C) Icon.Net Pty Ltd, Brisbane, Australia, 2007, ISBN 978-0-9804262-9-8

Arayici, Y. and Sarshar, M. (2002) DIVERCITY: A VIRTUAL CONSTRUCTION DESIGN \& BRIEFING ENVIRONMENT, in Decision Making in Urban and Civil Engineering by Khosrowshahi, F. (ed), isbn 0904354474London 2002 pp 1057-1064.

Aydinalp M, Ugursal VI, Fung AS. Modeling of the appliance, lighting and space-cooling energy consumptions in the residential sector using neural networks. Applied Energy, 2002, 71: 87-110.

Barker, Roger G., (1968), Ecological Pyschology: Concepts and Methods for Studying the Environment of Human Behaviour, Stanford, Calif.: Stanford University Press, 1968.

Barley N., (1992) Design in a tribal context, Journal of Design History vol.5, no.2 (1992) pp.103-111.

Baumann, H., Tillman, A.-M., (2009), The Hitch Hiker's Guide to LCA, Studentlitteratur AB, 2009

BSI, (2012), BS EN ISO 14040:2006 Environmental Management. Life Cycle Assessment. Principles and Frameworks, BSI, 2006, viewed 25th June 2012, http://shop.bsigroup.com

Bromilow, F. J., Dwer, P. W., Pawsey, M. R., Taylor, R. J., and Tucker, S. N. (1984) A national system for building lifecycle performance data recording, National committee on Rationalised building, Highett.
Capper, G., Matthews, J. and Lockley, S., (2012) Incorporating embodied energy in the BIM process, CIBSE ASHRAE Technical Symposium, Imperial College, London UK - 18th and 19th April 2012

Card, S. K. Mackinlay, J. D.; and Shneiderman, B. 1999. Readings in Information Visualization: Using Vision To Think. Morgan Kaufmann.

Chapin, F. Stuart, Jr., (1968), Activity systems and urban structure; a working schema, The journal of the American Institute of Planners, Vol. 34, 34 (Jan 1968)

Chen, C. 1999. Information Visualisation and Virtual Environments. Springer.

Chinyio, E and Gameson, R (2009) Private finance initiative in use. In: A. Akintoye and $\mathrm{M}$.

Beck, (eds.) Policy finance and management for publicprivate partnerships. UK:

Wiley-Blackwell.

Dreyfuss, Henry, (1967), The Measure of Man: Human Factors in Design, $2^{\text {nd }}$ ed., New York: Whitney Library of Design, 1967

Dawood, N. and Mallasi, Z. (2006), Construction Workspace Planning: Assignment and Analysis Utilizing 4D Visualization Technologies, Computer-Aided Civil and Infrastructure Engineering 21 (2006) 498-513

Finnveden G, Hauschild M, Ekvall T, Guinée J, Heijungs R, Hellweg S, Koehler A, Pennington D, Suh S., (2009), Recent Developments in Life Cycle Assessment, J. Envir. Man., 2009, 91(1): 1-21.

Flanagan, L (2002) Lifecycle Assessment as a Decision Making Tool, In: Khosrowshahi, F. (Ed.) Decision Making in urban and Civil Engineering London, 211-218.

Flanagan, R. and Norman, (1983), G. Lifecycle costing for construction. London: Royal Institute of Chartered Surveyors, 1983.

Froese, T., Han, Z. and Alldritt, M. (2007) Study of Information Technology Development for the Canadian Construction Industry, Canadian Journal of Civil Engineeringm 34(7), 2007, pp.817-829

Gil $\mathrm{N}$ and Beckman S, Infrastructure meets business: Building new bridges, mending old ones. California Management Review, 51(2), 6-29, 2009

Griffin, M., (1995), Applications of VR in architecture and design. Proceeding of the Information Technology Awareness Workshop., University of Salford, January 1995.

Hall, Edward T., (1962), The maddening crowd: space and its organization as a factor in mental health, Landscape, Vol. 12, 26-30, (Autumn 1962)

Hall, Edward T., (1966), The Hidden Dimension, Garden City, N.Y.: Doubleday, 1966.

Holness G. (2008) Building Information Modeling: Gaining Momentum, ASHRAE Journal, 2008, 50(6): 28-37.

Haymaker, J., and Fischer, M. (2001). "Challenges and benefits of 4D modelling on the Walt Disney Concert Hall 
Project." Working Paper \#064, CIFE, Stanford University, Stanford, CA.

International Standard ISO/IEC 14772-1:1997, The VRML Consortium Incorporation, 1997.

International Standardisation Organisation 14040, Environmental management - life cycle assessment principles and framework, 2006

Jha, M. K. (2006) Feasibility of Computer Visualization in Highway Development: A Fuzzy Logic-Based Approach, Computer-Aided Civil and Infrastructure Engineering 21 (2006) 136-147

Jones, K., and Collis, C. (1996) On the role of computerised maintenance management systems, Property Management, vol. 14, no. 4, MCB University Press.

Jones, K., Burrows, C. and Collis, S. (1999) Computerised maintenance management systems: a survey of performance requirements, RICS paper series, vol. $\mathbf{3}$, no. 5. May.

Jordan, A. T., (1995) Managing diversity: Translating anthropological insight for organization studies, Journal of Applied Behavioral Science [JBS] ISSN: 0021-8863, Vol: 31 Iss: 2 Date: Jun 1995 p: 124-140

Kamat, V. R., \& Martinez, J. C. (2001). Visualizing simulated construction operations in 3D. Journal of Computing In Civil Engineering, 15(4), 329-337.

Kamat, V. R. and Martinez, J. C. (2002) Scene Graph and Frame Update Algorithms for Smooth and Scalable 3D Visualization of Simulated Construction Operations, Computer-Aided Civil and Infrastructure Engineering 17, 228-245

Kang, S. and Miranda, E. (2009) Numerical methods to simulate and visualize detailed crane activities. ComputerAided Civil and Infrastructure Engineering, 24, 169-185

Keoleian G, Blanchard, S, Reppe, P., (2001) Life Cycle Energy, Costs, and Strategies for Improving a Single Family House, J. Indust. Ecol., 2001, 4(2): 135-156.

Khosrowshahi, F. and Alani, A. (2011) Visualisation of Impact of time on the internal lighting of a building, Automation in Construction (impact factor 1.372) Elsevier B.V. Vol 20 Number 2, March 2011, pp145 - 154, ISSN 0926-5805

Khosrowshahi, F and Alani, M (2003) Event and effect model of building maintenance. In: Greenwood, D J (Ed.), 19th Annual ARCOM Conference, 3-5 September 2003, University of Brighton.

Khosrowshahi, F. and Banissi, E., (2001) Visualisation of the Degradation of Building Flooring Systems in Information Visualisation, Edited by $\mathrm{E}$. Banissi, M. Khosrowshahi, F., Sarfraz M. and Ursyn, A., IEEE, Computer Society, Los Alamitos, California, ISBN 07695 1195 - 3, 507-513.

Koomey, J. G., (2011), Growth in Data Center Electricity Use 2005 to 2010, 2011, viewed $1^{\text {st }}$ February 2012, http://www.analyticspress.com/datacenters.html
Krygiel E, Nies B. (2008). Green BIM: Successful Sustainable Design with Building Information Modeling, Wiley, 2008.

Kuhner, S., Crouse, B. and Rank, R. (2004), From a Product Model to Visualization: Simulation of Indoor Flows with Lattice-Boltzmann Methods, Computer-Aided Civil and Infrastructure Engineering 19, 411-420

Lang, J. (1974), Designing for human behaviour, Dowden, Hutchinson \& Ross, Stroudsburg, PA.,1974.

Lapin, L.L., (1990) Probability and Statistics for Modern Engineering, Thomson information/ publishing group, Boston, 1990.

Lipman, R and Reed, K (2000), Using VRML In Construction Industry Applications, Web3D - VRML 2000 Symposium, Monterey, CA, February 21-24, 2000

Martinez-Ortiz, C., Pearson, D., Beck, M., Barlow, N. and De Wilde, P. (2012), Developing automated energy management tools, CIBSE ASHRAE Technical Symposium, Imperial College, London UK - 18th and 19th April 2012

Nardi B. A. and Reilly B., (1996) Interactive ethnography: beyond being there, Innovation vol.15, no.2 (Summer 1996) pp.22-25

Ng, S T, Shi, J and Fang, Y (2009) Enhancing the logistics of construction materials through activity-based simulation approach. Engineering, Construction and Architectural Management, 16(3), pp. 224-37.

Olofsson T, Andersson S, Sjögren JU. Building energy parameter investigations based on multivariate analysis. Energy and Buildings, 2009, 41: 71-80.

Pitts A, (2008) Future proof construction - Future building and systems design for energy and fuel flexibility. Energy Policy, 36(12), 4539 - 4543, 2008

Pettit, R. (1983) Computer aids in the management of maintenance, Building Maintenance Information Report, RICS BMI, London.

Puntenney, P J (1995) Informing environmental policy making Journal of Futures [FUR] ISSN: 0016-3287, Vol: 27 Iss: 6 Jul/Aug 1995 p: 675-680

Rangaraju, N. and Terk, M. (2001) Framework for immersive Visualisation of Building Analysis Data, in Banissi, E, Khosrowshahi, F., Sarfaraz, M. and Ursyn, A., IV2001, Information Visualisation, IEEE Computer Society Los Alamitos, California, 2011, pp37-43.

Rapp, R. and George, B. (1998) Maintenance management concepts in construction equipment curricula. Journal of Construction Education, 2(2), 155-69.

Rekapalli, P. V., Martınez, J. C. and Kamat, V. R. (2009), Computer-Aided Civil and Infrastructure Engineering 24, 186-198

Rhodes, A., J., (2012) Energy Metering and Visualization Project for the San Francisco Office, CIBSE ASHRAE Technical Symposium, Imperial College, London UK - 18th and 19th April 2012 
RICS (2009) Building Maintenance: Strategy, Planning and Procurement. London: Royal

Institution of Chartered Surveyors.

Robinson, J., (1984), Lifecycle costing in buildings: a practical approach. Australian Institute of Building Papers, 1: $13-28,1984$

Robinson, N. and Nims, J. (1996) Anthromics: insight into what really matters. Innovation vol.15, no.2 (Summer 1996) pp.18-21

Rosenman, M. A., Smith, G., Maher, M. L., Ding, L. and Marchant, D. (2007) Multidisciplinary Collaborative Design in Virtual Environments, Automation in Construction, 16(1), 2007, pp. 37-44

Russell P and Moffatt S, Adaptability of Buildings, IEA Annex 31 Energy-Related Environmental Impact of Buildings, University of Karlsruhe, 2001

Scheuer C. Keoleian G., (2001), Evaluation of LEED Using Life Cycle Assessment Methods, National Institute of Standards and Technology, NIST GCR 02-836.

Schensul J. J.,(1996) Cultural assessment: a whole new world of meaning, Innovation vol.15, no.2 (Summer 1996) pp.14-16.

Shah, A., Lugo, W., Patel, C., (2010), ThermodynamicsBased Object-Oriented Environmental Design of an Industrial Air Conditioner, ASME 2009 Heat Transfer Summer Conference, San Francisco, California, USA, ASME, 2009, viewed 11th June 2010, http://www.asmedl.org/

Shen, W., Qi, H., Helium, M., Neelamkavil, J., Xie, H, Dickinson, J., Thomas, A., Pardasani, A. and Xue, H. (2010) Systems Integration and Collaboration in Architecture, Engineering, Construction, and Facilities Management: A review, Advanced Engineering Informatics, Volume 24, Issue 2, April 20120, pp. 196-207, Enabling Technologies for Collaborative Design

Sommer, Robert, (1969), Personal Space: The behavioural Basis of design, Englewood Cliffs, N.J.: Prentice-Hall, 1969.

Spedding, A. (1994) Documentation and cost-effective management of property, in Spedding, A. (ed.) CIOB Handbook of Facilities Management, Longman Group Limited, Essex.

Spence, R. 2001. Information Visualization. AddisonWesley.

Stone, P.A., (1980) Building Design Evaluation: costs-inuse. (3ed) London, Spon, 1980.

Sustainable Energy Management and the Built Environment SEMBE, Powering our Lives:, Foresight, Government Office for Science, London, 2008

Tregenza, P. (1976) The design of interior circulation: People and buildings, Crosby Lockwood Staples (London), ISBN 0258969989.

VRML 2.0 Final Specification, "http:// www.vrml.org/ VRML2.0/FINAL"
WCED, Our Common Future, Brundtland World Commission on Environment and Development, Oxford University Press, Oxford, 1987

Wilcox S. B., (1996) Why anthropology: a tool for design research, Innovation vol.15, no.2 (Summer 1996) pp.10-11.

Whitehead, B., Tozer, R., Shah, A., Kosik, B., Maidment, G., Andrews, D. and Dunn, A., (2012) The Environmental Burden of Data Centres - A Screening LCA Methodology, CIBSE ASHRAE Technical Symposium, Imperial College, London UK - 18th and 19th April 2012

Waheed, Z. and Fernie, S. (2009) Knowledge based facilities management. Facilities, 27(7/8), pp. 258-266.

Wordsworth, P. (2001) Lee's Building Maintenance Management, Blackwell Science, London.

Zabalza Bribián I, Aranda Usón A, Scarpellini S, Life cycle assessment in buildings: State-of-the-art and simplified LCA methodology as a complement for building certification. Buildings and Environment, 44(12), 2510 2520, 2009

Zhang, J., Yu, F., Li, D. and Hu, Z. (2012), Development and Implementation of an Industry Foundation ClassesBased Graphic Information Model for Virtual Construction, Computer-Aided Civil and Infrastructure Engineering 00, $1-15$ 